\title{
Prevalence of antibiotic resistant bacteria isolated from raw chicken meat
}

\author{
Sarannia Thanganathan, Astha Latchumi Sanglidevan and Kamariah Hasan* \\ School of Biological Sciences, Faculty of Science and Technology, Quest International University Perak, Plaza Teh \\ Teng Seng, Jalan Raja Permaisuri Bainun 30250, Ipoh, Perak, Malaysia. \\ Email: kamariah@qiup.edu.my
}

Received 7 November 2019; Received in revised form 28 February 2020; Accepted 30 March 2020

\begin{abstract}
Aims: Antibiotics are widely used in poultry industry for treatment, control and in preventing the spread of infectious diseases among chicken flocks. The uncontrolled use of antibiotic causes the emergence of antibiotic resistant bacteria which is a major concern worldwide. The aim of this study is to isolate and molecularly identify antibiotic resistant bacteria using raw chicken meat samples from farm, supermarket, wet market as well as free-range chicken.

Methodology and results: A total of 34 isolates were obtained through primary screening based on their ability to grow on streptomycin, kanamycin, ampicillin and cefazolin antibiotic plates. Kirby-Bauer disc diffusion test performed on the 34 isolates showed that they were highly resistant to oxacillin $(97 \%)$ and penicillin $(94 \%)$ followed by ampicillin (64\%), cefazolin (50\%), tetracycline (32\%), erythromycin (24\%), ciprofloxacin (21\%) and least resistance towards gentamycin $(6 \%)$. Eight isolates with the highest antibiotic resistance, were selected for molecular identification using 16S rDNA sequencing. Analysis of the 16S rDNA sequence using BLASTN and phylogenetic tree constructed on the selected isolates revealed that five different species of antibiotic resistant bacteria namely Escherichia coli, Klebsiella sp., Chryseobacterium gleum, Comamonas testosteroni and Bacillus cereus were successfully identified from the different types of chicken sample.

Conclusion, significance and impact of study: The excessive use of antibiotic in the poultry farm industries had caused the emergence of antibiotic resistant bacteria which can harm the health of people consuming chicken meat. To overcome this crisis, antibiotic usage in the poultry farm industries should be regulated.
\end{abstract}

Keywords: 16S rDNA, antibiotic resistant bacteria, Kirby-Bauer disc diffusion, poultry industry

\section{INTRODUCTION}

The economic and health benefits of using antibiotics have transformed poultry and livestock production intensively. Previously, the use of antibiotics was mainly focused in overcoming infectious diseases and restoring human health but as time goes on, poultry producers saw the importance of using antibiotics to prevent infectious diseases in animals (Castanon, 2007). However, the overuse of antibiotics in poultry industry can lead to the emergence of antibiotic resistant bacteria that has caused a viral public health concern in many countries (Lior and Bjerrum, 2014). Government from all around the world are beginning to pay attention to the rise of antimicrobial resistance within wide range of infectious agents as it threatens the achievements of modern medicine (Roca et al., 2015).

The emergence of bacterial foodborne pathogens resistant to antibiotics reflects evolutionary processes that take place as animals are being exposed to antibiotics (Adzitey, 2015). Resistance of foodborne pathogen to antibiotics can occur by inheritance of resistant gene due to horizontal gene transfer especially in location of frequent antibiotic use such as hospitals and farms (Adzitey, 2015; Witte, 2004). When an antibiotic is used in poultry farming, the drug eradicates the sensitive bacterial strains, leaving behind those variants with unusual traits that can resist it. These resistant bacteria then proliferate, growing their numbers and becoming the major microorganism in the population.

The development of antibiotic resistance threatens not only the effective prevention but also the treatment of an ever-increasing range of infections. It has reduced the effectiveness of available antibiotics. Thus, the treatment of patient with antimicrobial resistance disease has become more difficult, costly or even impossible. The issues of antibiotic resistant bacteria have become a complex global public health challenge. The development and implementation of effective strategies to overcome the emergence and spread of antibiotic resistant bacteria in poultry industries depend on the collection of accurate information. In order to evaluate the effect of antibiotic resistant bacteria on human, it is necessary to collect information on the evolution, extent and impact of 
emerging antibiotic resistant bacteria.

This research focused on the isolation and molecular identification of antibiotic resistant bacteria from raw chicken meat obtained from farm, wet market, supermarket and free-range chicken. The result of this study will help to overcome the lack of information especially on the emergence of antibiotic resistant bacteria due to excessive and unregulated use of antibiotics in farming especially in Perak State. Hopefully this study will prompt others to perform similar research, so that a collective result can be obtained that represent the emerging of bacterial foodborne pathogens resistant to antibiotics in Malaysia.

\section{MATERIALS AND METHODS}

\section{Sample collection}

Four raw chicken meat samples were collected where the first and second samples were farm chicken and freerange chicken collected from Pusat Latihan dan Penternakan Haiwan Banir, Tapah, Perak. Third sample was obtained from Tapah wet market and the fourth sample was obtained from Econsave Supermarket located in Jalan Raja Permaisuri Bainun, Ipoh.

\section{Isolation of microbes}

Approximately $1 \mathrm{~g}$ of fresh raw chicken meat (breast part) obtained from the four different sources was finely chopped using a sterile blade and $1 \mathrm{~mL}$ of peptone water was added to aid in fine mincing procedure. The minced raw chicken meats were added into $9 \mathrm{~mL}$ of peptone water. Serial dilution was performed up to $10^{6}$ and $100 \mu \mathrm{L}$ from each of the diluted sample was spread on streptomycin, ampicillin, kanamycin and cefazolin antibiotic plates with $50 \mu \mathrm{g} / \mathrm{mL}$ concentration. The plates were incubated for $24 \mathrm{~h}$ at $37{ }^{\circ} \mathrm{C}$. Sub-culturing was performed to obtain pure single colony of bacteria. Based on the colony morphology, 10 different strains from each antibiotic used were sub-cultured and labeled according to the sources.

\section{Kirby-Bauer disc diffusion test}

Ten bacterial isolates from each chicken meat sample that showed resistant to antibiotic from primary screening were selected for Kirby-Bauer disc diffusion test. The colonies were suspended in $5 \mathrm{~mL}$ of peptone water to obtain bacterial density similar to $0.5 \mathrm{McFarland}$ standard. The inoculum was spread on the surface of Mueller-Hinton agar. Eight different types of antibiotic discs were placed on the agar surface using sterile forcep. Three discs (triplicate) were used for each antibiotic to obtain accurate zone of resistance for data analysis. The antibiotics used were tetracycline $(30 \mu \mathrm{g})$, cefazolin $(30 \mu \mathrm{g})$, penicillin (1 unit), erythromycin $(15 \mu \mathrm{g})$, oxacillin $(1 \mu \mathrm{g})$, ciprofloxacin $(1 \mu \mathrm{g})$, ampicillin $(25 \mu \mathrm{g})$ and gentamycin $(25 \mu \mathrm{g})$. The plates were incubated at $37^{\circ} \mathrm{C}$ for $24 \mathrm{~h}$. Clear zones can be observed which indicated that the isolated bacteria were not resistant towards the antibiotic discs used. The clear zones were measured, and data analysis was carried out to obtain strains with the highest resistance against the antibiotic used. One-way Anova analysis was carried out using the Minitab program by comparing the antibiotic resistance zone.

\section{Identification of bacteria}

The isolates were primarily identified at microscopy level using Gram staining. Two isolates from each source that showed the highest resistance toward antibiotics following Kirby-Bauer disc diffusion test were molecularly identified using $16 S$ rDNA sequence. 16S rDNA gene was amplified using the forward primer $68 \mathrm{~F}\left(5^{\prime}\right.$ TNANACATGCAAGTCGAKCG-3') and reverse primer 1392R (5'-ACGGGCGGTGTGTRC-3'). PCR reaction was performed as follows; $94{ }^{\circ} \mathrm{C}$ for $3 \mathrm{~min}$, followed by 35 cycles of denaturation at $94^{\circ} \mathrm{C}$ for $30 \mathrm{sec}$, annealing at 55 ${ }^{\circ} \mathrm{C}$ for $30 \mathrm{sec}$ and elongation at $72{ }^{\circ} \mathrm{C}$ for $90 \mathrm{sec}$. Next, the PCR tubes were incubated for an additional elongation for $10 \mathrm{~min}$ at $72^{\circ} \mathrm{C}$ and the reaction was maintained at $4{ }^{\circ} \mathrm{C}$. The PCR products were analyzed using gel electrophoresis.

\section{DNA sequencing}

The PCR products were sent to First BASE Laboratories Sdn. Bhd. for sequencing. The resulting sequences were first trimmed using sequence scanner software 2.0 version. Then, the sequences were compared using NCBI nucleotide database. The matched sequences were checked for the presence of gaps and the sequences were trimmed and compared again in order to obtain a higher possibility percentage of the isolated bacteria species with available database.

\section{Phylogenetic analysis}

Phylogenetic analysis was performed for all eight isolates using 16S rDNA sequences obtained. MEGA 6.06 software was used to construct Maximum likelihood tree using the best model and suitable outgroup was added.

\section{RESULTS AND DISCUSSION}

\section{Isolation of bacteria}

Initial screening using plates supplemented with antibiotics ampicillin and cefazolin showed high resistance of bacterial cultures isolated from farm chicken as lawn of bacterial growth were observed on both antibiotic plates (Figure 1). On the other hand, isolated bacterial colonies were observed on antibiotic plates cultured with samples with no dilution which showed that bacteria isolated from farm chicken are more susceptible towards kanamycin and streptomycin. Bacteria isolated from supermarket chicken showed a lower resistance towards all four antibiotics. Bacterial colonies from samples with $10^{\circ}$ and $10^{1}$ dilutions can be seen on all antibiotic plates, while 
Malays. J. Microbiol. Vol 16(4) 2020, pp. 302-311

DOI: http://dx.doi.org/10.21161/mjm.190633
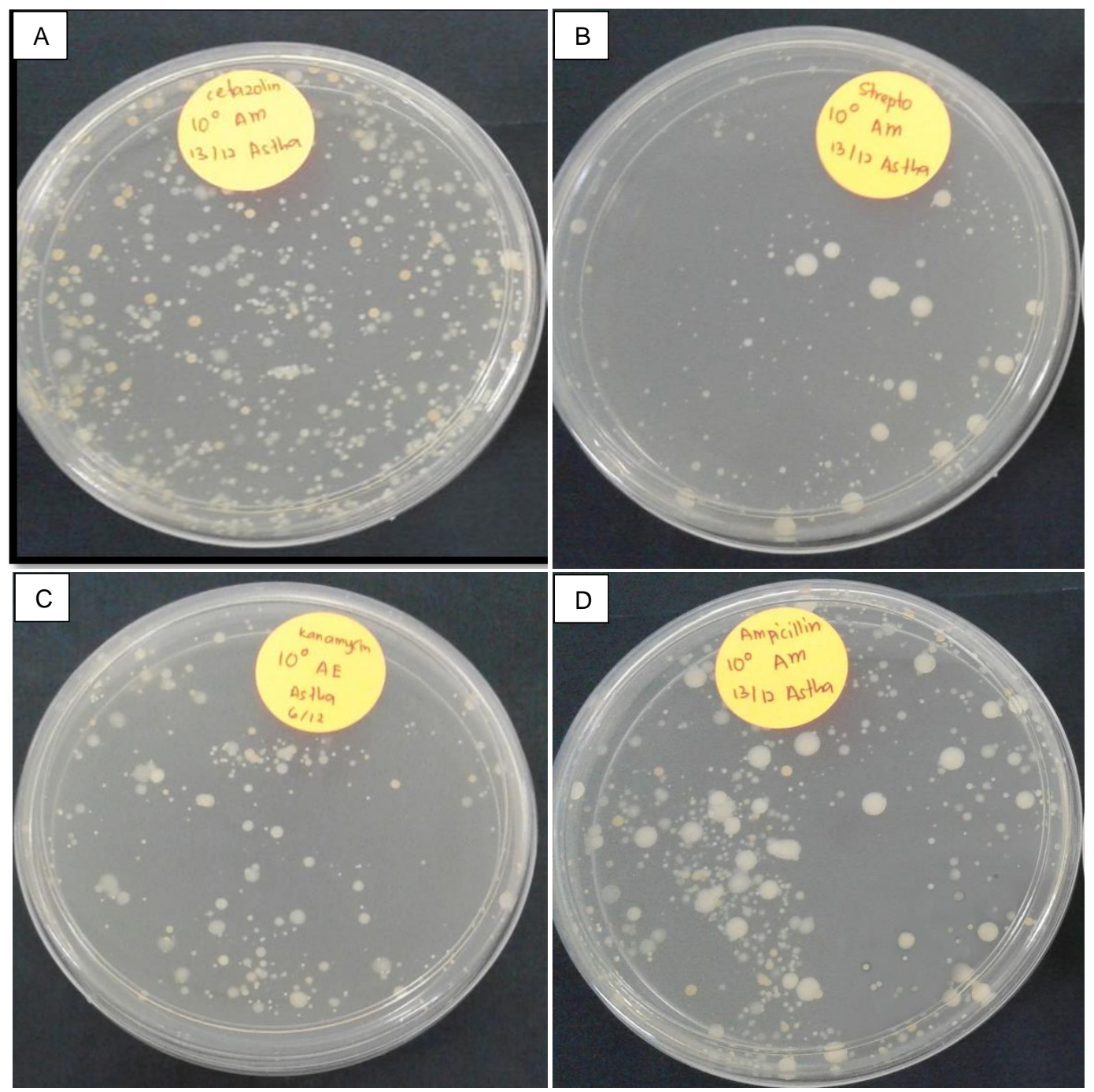

Figure 1: Primary screening for antibiotic resistant bacteria using nutrient agar supplemented with different antibiotics. (A) Cefazolin (B) Streptomycin (C) Kanamycin and (D) Ampicillin.

sample from higher bacterial dilution were unable to grow on the antibiotic plates. Many different types of colonies were observed with different color, morphology and texture. Most of the bacteria isolated from supermarket chicken formed transparent-like or white colored colonies.

The bacterial colonies isolated from the wet market chicken were more resistant towards cefazolin compared to the other three antibiotics. The bacteria showed a lower resistant against streptomycin as less number of colonies were observed on the plate. From the results obtained, the highest resistant was observed in cefazolin plate followed by ampicillin, kanamycin and lowest resistance was observed in streptomycin plates. On the other hand, the number of bacterial colonies isolated from free-range chicken was far less compared to number of colonies isolated from other chicken samples. Most of the bacterial colonies were observed only in two plates which were from dilution of $10^{0}$ and $10^{-1}$ indicating that these bacteria are more susceptible to antibiotics. Amongst the antibiotics used, bacterial colonies isolated from freerange chicken showed the highest resistant against cefazolin. However, a smaller number of colonies were observed on streptomycin plate compared to other antibiotics plates which indicate that, bacteria isolated from free-range chicken have lower resistant towards streptomycin.

In total, 34 bacterial isolates were obtained from initial screening which consists of 10 isolates from each farm and wet market chicken, 8 isolates from supermarket chicken and 6 isolates from free-range chicken. The different colonies were chosen for subsequent KirbyBauer disc diffusion test based on their color, morphology and texture. 


\section{Kirby-Bauer disc diffusion test}

Kirby-Bauer disc diffusion test was performed for the 34 isolates using eight different types of antibiotic discs including tetracycline, cefazolin, penicillin, erythromycin, oxacillin, ciprofloxacin, ampicillin and gentamycin. When the antibiotic discs were placed on the surface of the agar, water from the agar will be absorbed by the discs which allow the antimicrobial agent to diffuse into the surrounding agar (Vineetha et al., 2015). After $24 \mathrm{~h}$ incubation, the absence or presence of bacterial growth around antibiotic discs were observed, as it is an indirect measure of the bacteria's ability to survive against antibiotic used. Clear zone observed around the disc indicates that the bacteria are susceptible towards the antibiotic used in this study. The clear zones were measured and recorded as shown in Table 1 for all isolates obtained from farm chicken, supermarket chicken, wet market chicken and free-range chicken. The clear zones observed ranges from $0.6 \mathrm{~cm}$ to $3.1 \mathrm{~cm}$ in size.

All 34 isolates were resistant to at least one type of antibiotic disc used and more than half of the isolates possessed multiple antibiotic resistance. Out of the 34 isolates, 33 were resistant to oxacillin (97\%) and 32 were resistant towards penicillin (94\%). Thus, the highest resistance was shown by the isolates towards oxacillin and penicillin. A lower resistance was shown towards gentamycin, ciprofloxacin, erythromycin and tetracycline as shown in Table 2. Only two isolates obtained from farm and supermarket chickens were resistant towards gentamycin whereas seven isolates were resistant towards ciprofloxacin.

Table 1: Zone of resistant shown by the bacterial colonies isolated from the farm chicken $(R)$, supermarket chicken (E), wet market chicken $(\mathrm{M})$ and free-range chicken $(\mathrm{K})$.

\begin{tabular}{|c|c|c|c|c|c|c|c|c|}
\hline \multirow[b]{2}{*}{ Strain } & \multicolumn{8}{|c|}{ Zone of resistant $(\mathrm{cm})$} \\
\hline & Ampicillin & Gentamycin & Erythromycin & Penicillin & Cefazolin & Oxacillin & Ciprofloxacin & Tetracycline \\
\hline $\mathrm{R} 1$ & - & $1.60 \pm 0.06$ & - & - & - & - & - & - \\
\hline $\mathrm{R} 2$ & $3.07 \pm 0.03$ & - & - & $1.33 \pm 0.03$ & $3.07 \pm 0.03$ & - & - & - \\
\hline R3 & $1.70 \pm 0.06$ & $2.37 \pm 0.09$ & - & $1.13 \pm 0.03$ & $2.57 \pm 0.03$ & $1.30 \pm 0.00$ & - & - \\
\hline $\mathrm{R} 4$ & - & $2.13 \pm 0.03$ & - & - & $1.87 \pm 0.03$ & - & - & - \\
\hline $\mathrm{R} 5$ & - & $1.93 \pm 0.03$ & $0.83 \pm 0.03$ & - & - & - & $2.77 \pm 0.09$ & $1.43 \pm 0.03$ \\
\hline R6 & - & $2.53 \pm 0.03$ & $1.33 \pm 0.09$ & - & - & - & $2.07 \pm 0.03$ & $1.70 \pm 0.06$ \\
\hline R7 & $1.33 \pm 0.09$ & $1.60 \pm 0.06$ & $0.73 \pm 0.03$ & - & - & - & $2.23 \pm 0.07$ & - \\
\hline $\mathrm{R} 8$ & - & $1.80 \pm 0.10$ & $2.37 \pm 0.03$ & - & $1.57 \pm 0.03$ & - & - & $2.37 \pm 0.17$ \\
\hline $\mathrm{R} 9$ & - & $1.97 \pm 0.03$ & $1.03 \pm 0.09$ & - & - & - & $1.00 \pm 0.06$ & $0.97 \pm 0.09$ \\
\hline $\mathrm{R} 10$ & - & $1.80 \pm 0.06$ & - & - & - & - & $2.10 \pm 0.06$ & $0.77 \pm 0.03$ \\
\hline $\mathrm{E} 1$ & - & $2.23 \pm 0.03$ & - & - & $1.87 \pm 0.03$ & - & - & - \\
\hline E2 & - & - & - & - & - & - & - & - \\
\hline E3 & $1.20 \pm 0.06$ & $2.03 \pm 0.03$ & $1.03 \pm 0.03$ & - & $2.20 \pm 0.06$ & - & $1.60 \pm 0.10$ & $0.87 \pm 0.09$ \\
\hline E4 & $1.00 \pm 0.06$ & $2.07 \pm 0.03$ & $0.97 \pm 0.03$ & - & $2.33 \pm 0.03$ & - & $2.40 \pm 0.10$ & $2.13 \pm 0.07$ \\
\hline E5 & $0.67 \pm 0.03$ & $2.57 \pm 0.03$ & $2.30 \pm 0.06$ & - & $0.77 \pm 0.09$ & - & $1.60 \pm 0.06$ & $0.90 \pm 0.06$ \\
\hline E6 & $1.73 \pm 0.07$ & $2.60 \pm 0.06$ & $1.27 \pm 0.03$ & - & - & - & $2.67 \pm 0.03$ & $2.20 \pm 0.06$ \\
\hline E7 & - & $2.47 \pm 0.03$ & $2.43 \pm 0.03$ & - & - & - & $2.67 \pm 0.09$ & $1.93 \pm 0.07$ \\
\hline E8 & $0.90 \pm 0.06$ & $2.37 \pm 0.03$ & $1.17 \pm 0.03$ & - & - & - & $2.60 \pm 0.06$ & $1.00 \pm 0.06$ \\
\hline M1 & $0.93 \pm 0.09$ & $2.00 \pm 0.06$ & $0.80 \pm 0.06$ & - & $2.30 \pm 0.06$ & - & $2.03 \pm 0.03$ & $1.87 \pm 0.03$ \\
\hline M2 & - & $1.23 \pm 0.03$ & $1.37 \pm 0.06$ & - & $\begin{array}{c}2.00 \pm 0.00 \\
-\end{array}$ & - & $1.80 \pm 0.06$ & $1.30 \pm 0.06$ \\
\hline M3 & $1.00 \pm 0.06$ & $0.53 \pm 0.03$ & $1.40 \pm 0.09$ & - & $2.53 \pm 0.09$ & - & $3.60 \pm 0.06$ & $2.77 \pm 0.03$ \\
\hline M4 & - & $2.17 \pm 0.08$ & $0.90 \pm 0.06$ & - & $2.23 \pm 0.09$ & - & $1.57 \pm 0.09$ & - \\
\hline M6 & - & $1.90 \pm 0.06$ & $0.77 \pm 0.03$ & - & $2.33 \pm 0.03$ & - & $2.47 \pm 0.03$ & - \\
\hline M7 & - & $1.53 \pm 0.03$ & $2.23 \pm 0.12$ & - & - & - & $2.10 \pm 0.06$ & $1,37 \pm 0.13$ \\
\hline M8 & - & $1.57 \pm 0.03$ & $1.97 \pm 0.03$ & - & - & - & $2.03 \pm 0.03$ & $1.90 \pm 0.10$ \\
\hline M9 & - & $1.50 \pm 0.06$ & $1.77 \pm 0.03$ & - & - & - & $2.00 \pm 0.06$ & $1.73 \pm 0.03$ \\
\hline M10 & - & $1.47 \pm 0.03$ & - & - & $1.67 \pm 0.03$ & - & $1.23 \pm 0.03$ & $1.40 \pm 0.06$ \\
\hline $\mathrm{K} 1$ & $0.73 \pm 0.03$ & $2.07 \pm 0.03$ & $1.47 \pm 0.03$ & - & $2.50 \pm 0.06$ & - & $3.07 \pm 0.03$ & - \\
\hline K2 & - & $1.53 \pm 0.03$ & $1.77 \pm 0.03$ & - & - & - & $1.90 \pm 0.06$ & $1.63 \pm 0.12$ \\
\hline K3 & - & $0.70 \pm 0.00$ & $0.70 \pm 0.06$ & - & $2.33 \pm 0.03$ & - & $1.47 \pm 0.03$ & $1.07 \pm 0.09$ \\
\hline K4 & - & $2.30 \pm 0.06$ & $0.87 \pm 0.03$ & - & $2.00 \pm 0.06$ & - & $1.50 \pm 0.06$ & - \\
\hline K5 & $0.70 \pm 0.00$ & $1.60 \pm 0.06$ & $0.90 \pm 0.06$ & - & - & - & $1.83 \pm 0.03$ & $2.00 \pm 0.06$ \\
\hline $\mathrm{K} 6$ & - & $1.60 \pm 0.06$ & $0.90 \pm 0.06$ & - & - & - & $1.83 \pm 0.03$ & $2.00 \pm 0.06$ \\
\hline
\end{tabular}


Malays. J. Microbiol. Vol 16(4) 2020, pp. 302-311

DOI: http://dx.doi.org/10.21161/mjm.190633

Table 2: Number of isolates which shows resistance against antibiotic disc used.

\begin{tabular}{|c|c|c|c|c|c|c|c|c|c|}
\hline $\begin{array}{l}\text { Chicken types } \\
\text { (isolates) }\end{array}$ & Ampicillin & Gentamycin & Erythromycin & Penicillin & Cefazolin & Oxacillin & Ciprofloxacin & Tetracycline & (a) \\
\hline $\begin{array}{l}\text { Farm chicken } \\
\text { (out of 10) }\end{array}$ & 7 & 1 & 5 & 8 & 6 & 9 & 5 & 5 & $58 \%$ \\
\hline $\begin{array}{l}\text { Supermarket } \\
\text { chicken } \\
\text { (out of } 8 \text { ) }\end{array}$ & 3 & 1 & 2 & 8 & 4 & 8 & 2 & 2 & $47 \%$ \\
\hline $\begin{array}{l}\text { Wet market } \\
\text { chicken } \\
\text { (out of } 10 \text { ) }\end{array}$ & 8 & 0 & 1 & 10 & 4 & 10 & 0 & 3 & $45 \%$ \\
\hline $\begin{array}{l}\text { Free range } \\
\text { chicken } \\
\text { (out of 6) }\end{array}$ & 4 & 0 & 0 & 6 & 3 & 6 & 0 & 1 & $42 \%$ \\
\hline (b) & $65 \%$ & $6 \%$ & $24 \%$ & $94 \%$ & $50 \%$ & $97 \%$ & $21 \%$ & $32 \%$ & \\
\hline
\end{tabular}

(a): Percentage of resistance shown by the isolates obtained from each chicken type.

(b): Total percentage of resistance shown by the 34 isolates towards each antibiotic used.

Bacterial isolates obtained from the farm chicken shows high resistance towards oxacillin, penicillin and ampicillin where $R 9, R 8$ and $R 7$ out of ten isolates showed resistance to the antibiotics, respectively. According to the Manual of Total Solution Provider (2012), penicillin is widely used to treat fowl cholera, a contagious disease caused by the bacterium Pasteutella multocida. Fowl cholera can range from acute septicemia to chronic and localized infection which leads to $100 \%$ morbidity and mortality (Alhendi et al., 2000). Overall, bacterial strains isolated from the farm chicken has the highest percentage of resistance (57.5\%) against the antibiotic disc used compared to those isolated from the supermarket, wet market and organic chicken which are more susceptible.

Among the four chicken samples, isolates obtained from free-range chicken showed the least percentage of resistance $(42 \%)$ compared to wet market chicken $(45 \%)$ and supermarket chicken (47\%). From the results obtained, the six isolates from the free-range chicken were susceptible towards gentamycin, erythromycin and ciprofloxacin. As for the farm chicken, four bacterial isolates out of ten were resistant towards erythromycin and ciprofloxacin. The isolates obtained from both supermarket and wet market chicken showed a 100\% resistance against penicillin and oxacillin.

By looking at the zone of resistance shown by the bacteria, an analysis was carried out to identify the bacterial strains with the highest resistant towards antibiotic discs used. One-way Anova analysis was performed between the zone of resistance and the bacterial strains using the Minitab software. Two bacterial strains were selected from each of the chicken sample which showed the highest resistant. From the output obtained, a total of 8 bacterial strains (E1, E2, R1, R4, K3, $\mathrm{K} 6, \mathrm{M} 9$ and M10) with highest resistant were chosen for molecular identification using 16S rDNA.

\section{Comparison of antibiotic resistant bacteria isolated from different source}

Based on the results obtained from this study, bacterial colonies isolated from the farm chicken showed high resistance towards antibiotic plates used compared to other types. During the primary isolation of antibiotic resistant bacteria isolated from farm chicken, lawns of bacteria was observed at zero dilution which indicates that the bacteria possess a high resistance against antibiotic used as compared to bacteria from other chicken samples.

Colonies isolated from the free-range chicken showed the least resistance towards antibiotic plate compared with other types of chicken samples. Although the organic chickens were raised without the use of any antibiotics, six strains which are resistant to antibiotics were isolated. Based on the result obtained from Kirby-Bauer method, 5 out of the 6 strains showed resistance towards more than two antibiotics. Free range and farm chicken meat samples were obtained from the same location, which was the Pusat Latihan dan Penternakan Haiwan Banir, thus there might be chances of cross contamination through poultry carcass and manure disposal. Buried farm chickens will release nutrient, pathogen and components of the carcass during the decomposition process into the soil. This process will eventually contaminate soil and surface water which provide an essential route for the transmission of antibiotic resistant bacteria from the farm chicken to the free-range chicken (Gerber et al., 2008).

The isolates obtained from both supermarket and wet market chicken showed $100 \%$ resistance against penicillin and oxacillin. This indicates that there might be possibilities that both of these antibiotics were used during the breeding process which causes the bacteria, within the chicken to develop resistance against the antibiotics. 


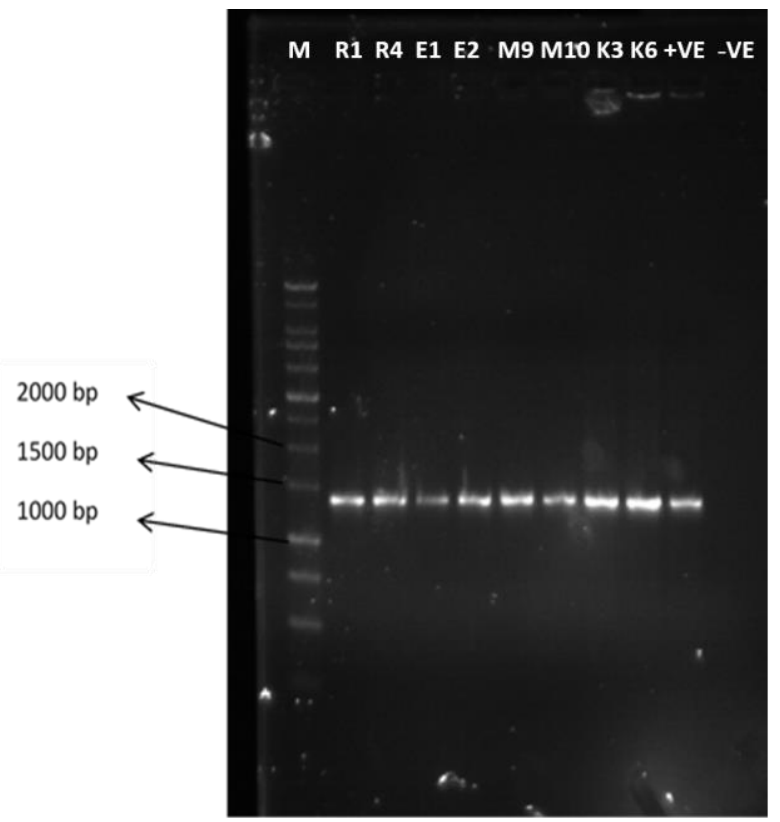

Figure 2: Agarose gel electrophoresis showing PCR fragments of $16 \mathrm{~S}$ rDNA gene amplified from 8 different strains (R1 to K6). The PCR fragments were $1324 \mathrm{bp}$ in size. $1 \mathrm{~kb}$ sharp DNA ladder was used as the marker. The size of bands of the marker is indicated with arrows.

\section{Molecular identification of isolates}

The PCR products of the amplification of 16S rDNA gene of all the eight isolates were resolved using agarose gel electrophoresis. The amplicons are 1324 base pair in size as shown in Figure 2.

\section{Phylogenetic tree analysis}

16S rDNA sequences of the eight samples were first analysed using NCBI BLAST. The results obtained from the analysis showed five different types of bacterial species isolated from four chicken samples. The five isolated species were Escherichia. coli, Klebsiella sp., Bacillus sp., Chryseobacterium sp. and Comamonas sp. Based on the BLAST analysis, suitable type strains were used to construct five phylogenetic trees as shown in Figure 3 to Figure 7. From the phylogenetic trees obtained, both R1 and R4 were shown to be closely related (Figure 3 ). Despite the close relation, $\mathrm{R} 1$ and $\mathrm{R} 4$ showed resistance against different types of antibiotics. Escherichia coli isolated from the farm chicken are almost similar with $E$. coli strain isolated from wastewater treatment plant (Accession No. KT275837) and newborn piglet (Accession No. KY678497). According to Gerber et al. (2008), improper poultry carcass disposal and poor poultry facilities causes the formation of bad odour that may attract flies, rodents and other domestic animals. This may lead to the spread of diseases in chicken caused by pathogenic bacteria.

Isolate $\mathrm{E} 1$ shows $100 \%$ similarity to Klebsiella sp. whereas $\mathrm{K} 3$ strain is closely isolated related to Klebsiella pneumonia obtained from freshwater (Accession No. KX233848.1) and activated sludge (Accession No. KX016030.1). Despite from the same genus (Klebsiella $\mathrm{sp}$.), both isolates were not closely related as shown in Figure 4. Isolate E1 possess resistance against ampicillin, erythromycin, penicillin, oxacillin, ciprofloxacin and tetracycline whereas isolate $\mathrm{K} 3$ possess resistance only against ampicillin, penicillin and oxacillin. Since K3 was obtained from free range chicken raised without the use of any antibiotic while E1 was obtained from supermarket chicken, there might be high chance of antibiotic usage during the breeding process for the latter.

Isolate E2 which was shown to be related to $B$. cereus showed antimicrobial property against beta-lactam group of antibiotics and a research conducted in the USA indicates that this bacterium had also developed resistance against tetracycline and erythromycin (Luna et al., 2007; Fiedler et al., 2019). Another research showed that 35 isolates of $B$. cereus obtained from 70 samples of fried rice in Malaysia exhibited a high resistance of about $88 \%$ towards streptomycin $(10 \mu \mathrm{g})$ and ampicillin $(30 \mu \mathrm{g})$ and $86 \%$ of resistant towards tetracycline $(30 \mu \mathrm{g})$. Furthermore, the isolated $B$. cereus showed $64 \%$ resistance against kanamycin $(30 \mu \mathrm{g}), 63 \%$ of resistance against vancomycin $(30 \mu \mathrm{g}), 57 \%$ resistance against gentamycin $(10 \mu \mathrm{g})$ and $42 \%$ resistance against erythromycin $(15 \mu \mathrm{g})$ and ciprofloxacin $(5 \mu \mathrm{g})$ (Jawad et al., 2016). Interestingly, isolate E2 obtained from this study also displayed resistance against the same antibiotics.

Based on Figure 6, isolates $\mathrm{K} 6$ and M9 are shown to be closely related to a bacterium, Chryseobacterium gleum which was isolated from the liver of a mouse (Jain et al., 2017). There are high chances of bacterial transmission from mouse to chicken through rat faeces and urine. Since isolate $\mathrm{K} 6$ was obtained from free-range chicken, there might be some possibility of the chicken consuming rat faeces contaminated with antibiotic resistant $C$. gleum. Both isolates $\mathrm{K} 6$ and $\mathrm{M} 9$ are resistance towards the same type of antibiotic disc used such as ampicillin, penicillin, oxacillin and cefazolin. Chryseobacterium sp. exhibits resistance against penicillin, a beta lactam antibiotic due to the presences of extended spectrum beta-lactamase (ESBLs) (Tanwar et al., 2014).

On the other hand, isolate M10 obtained from wet market showed close relationship to antibiotic resistant Comamonas testosteroni isolated from wastewater. Comamonas testosteroni, previously known as Pseudomonas testosteroni is a motile Gram-negative bacillus, non-spore forming and non-glucose forming bacteria (Tsui et al., 2009). Another study found that this bacterium can develop resistance towards antibiotic particularly streptomycin (Selvaraj et al., 2018). 


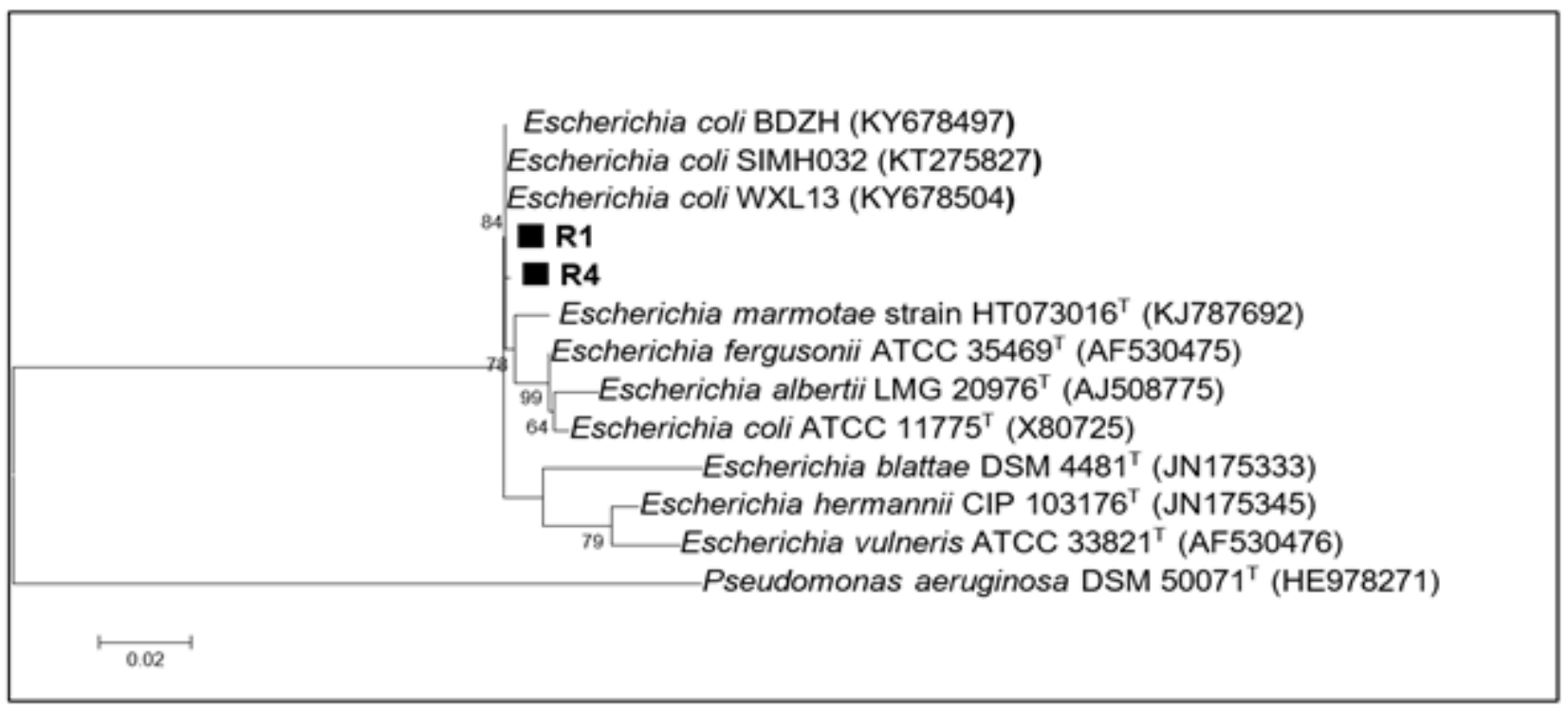

Figure 3: Maximum likelihood tree constructed using 16S rDNA gene sequences of R1 (1054 bp) and R4 (1006 bp) isolated from farm chicken. Pseudomonas aeruginosa was used as outgroup. This tree was constructed using MEGA6.06 software with Hasegawa-Kishino-Yano (HKY) with gamma distribution (G) model. GenBank accession numbers are in parentheses. The numbers on branches are bootstrap \% from 1,000 replications (shown only when $\geq$ $50 \%$ ). The scale bar shows $2 \%$ sequence divergence ( 2 substitutions per 100 nucleotides). The isolate R1 and R4 are indicated with $\square$. Superscript "T" indicates the type strains.

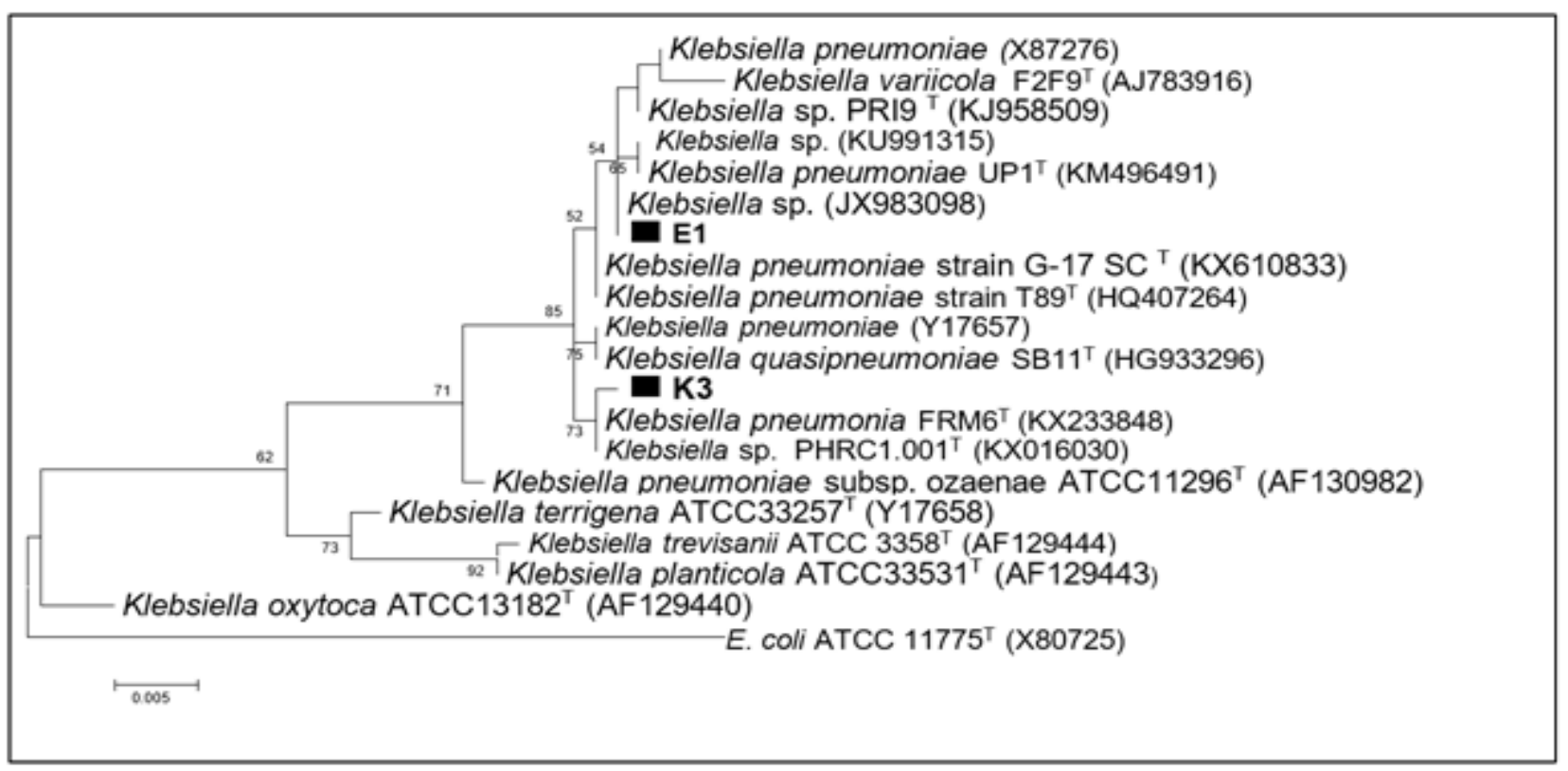

Figure 4: Maximum likelihood tree constructed using 16S rDNA gene sequences of E1 (909 bp) and K3 (1002 bp) isolated from supermarket and free-range chicken. Escherichia coli was used as outgroup. This tree was constructed using MEGA6.06 software with Hasegawa-Kishino-Yano (HKY) with gamma distribution (G) model. GenBank accession numbers are in parentheses. The numbers on branches are bootstrap \% from 1,000 replications (shown only when $\geq$ $50 \%$ ). The scale bar shows $0.5 \%$ sequence divergence ( 0.5 substitutions per 100 nucleotides). The isolate E1 and K3 are indicated with $\square$. Superscript "T" indicates the type strains. 


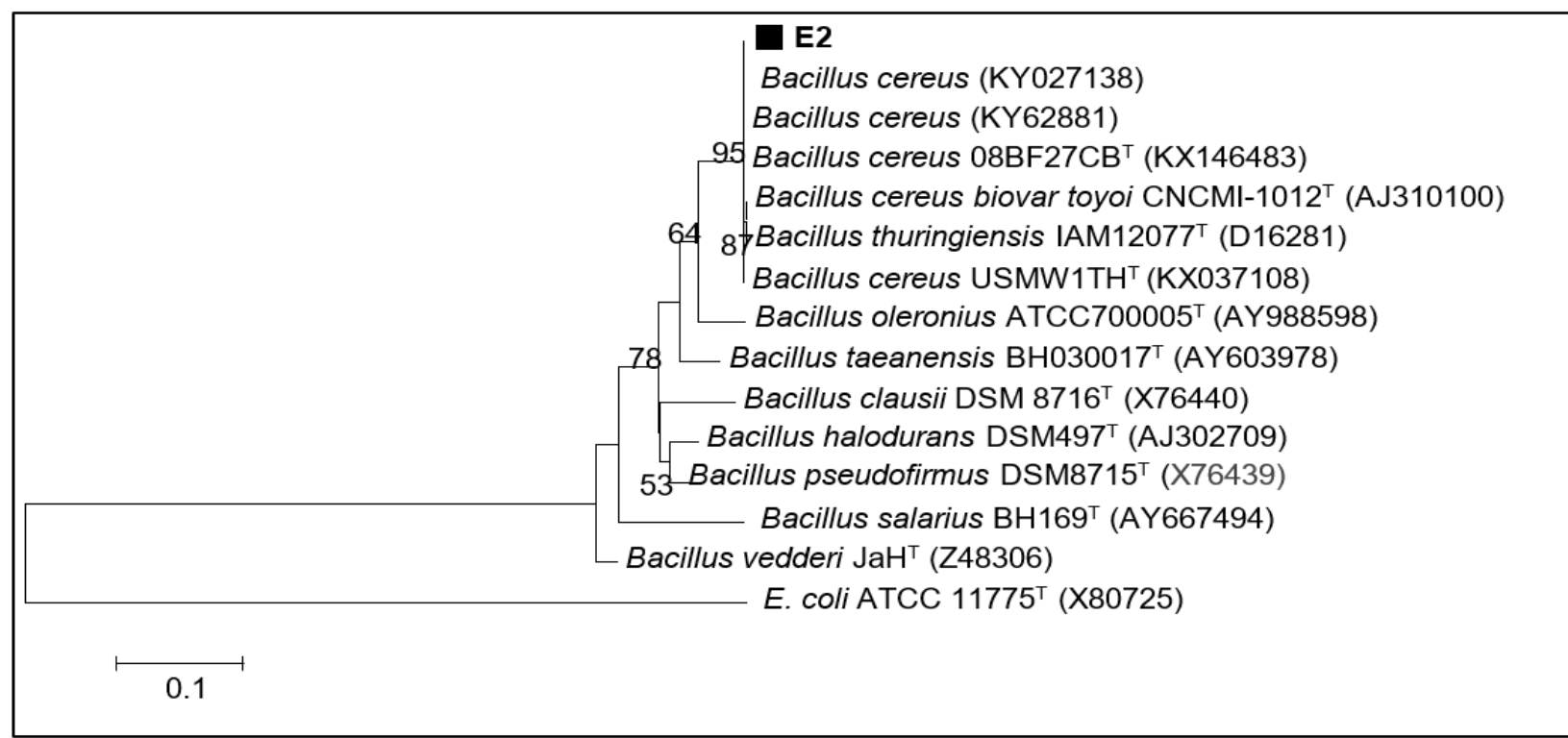

Figure 5: Maximum likelihood tree constructed using 16S rDNA gene sequences of E2 (978 bp) isolated from supermarket chicken. Escherichia coli was used as outgroup. This tree was constructed using MEGA6.06 software with Tamura-Nei (TN93) with gamma distribution (G) model. GenBank accession numbers are in parentheses. The numbers on branches are bootstrap \% from 1,000 replications (shown only when $\geq 50 \%$ ). The scale bar shows $10 \%$ sequence divergence (10 substitutions per 100 nucleotides). The isolate E2 is indicated with $\square$. Superscript "T" indicates the type strains.

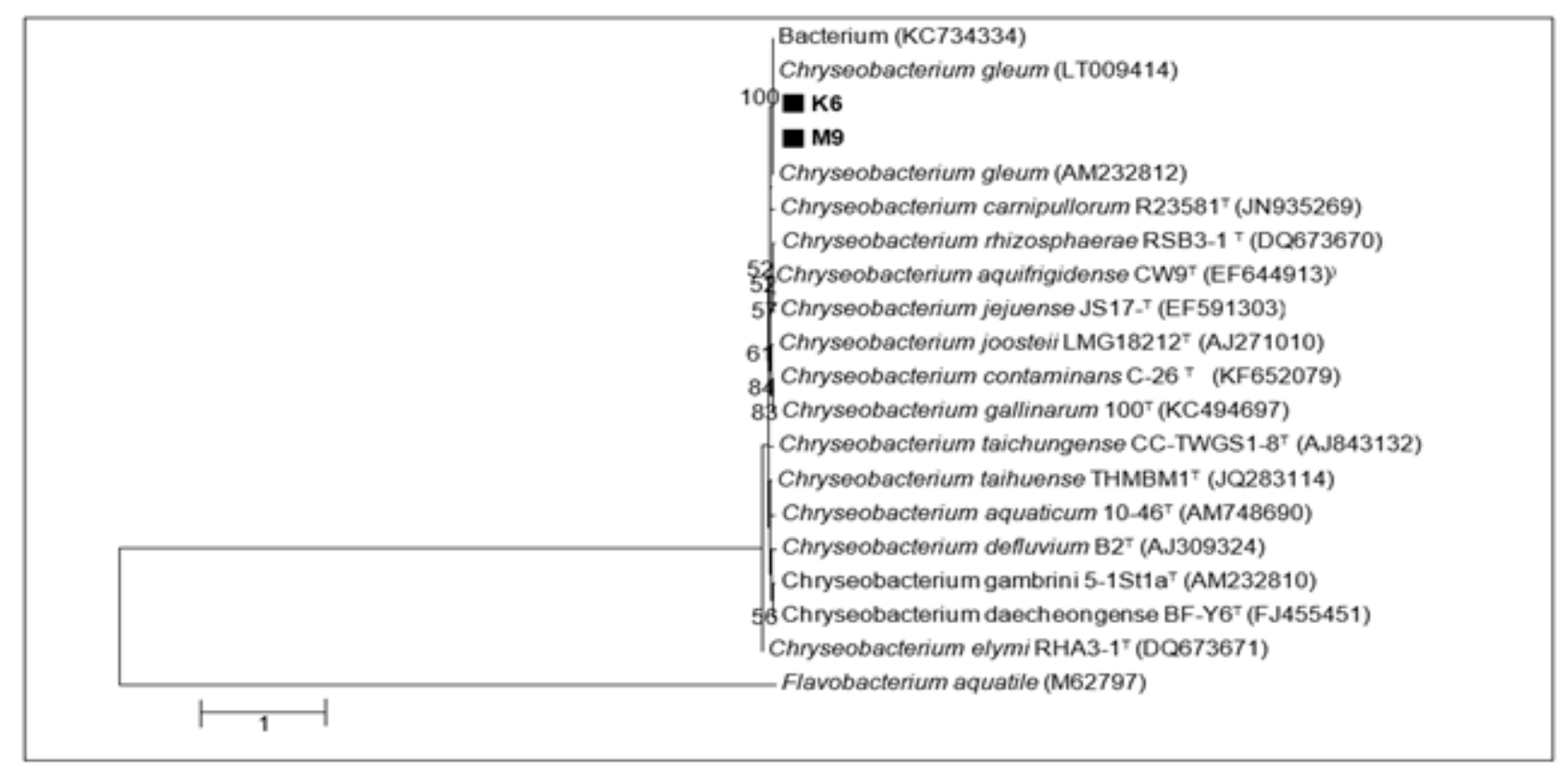

Figure 6: Maximum likelihood tree constructed using 16S rDNA gene sequences of M9 (977 bp) and K6 (890 bp) isolated from wet market and free-range chicken. Flavobacterium aquatile was used as outgroup. This tree was constructed using MEGA6.0 software with General Time Reversible (GTR) with gamma distribution with invariant sites $(\mathrm{G}+\mathrm{l})$ model. GenBank accession numbers are in parentheses. The numbers on branches are bootstrap $\%$ from 1,000 replications (shown only when $\geq 50 \%$ ). The scale bar shows $100 \%$ sequence divergence (100 substitutions per 100 nucleotides). K6 and M9 are indicated with $\square$. Superscript "T" indicates the type strains. 


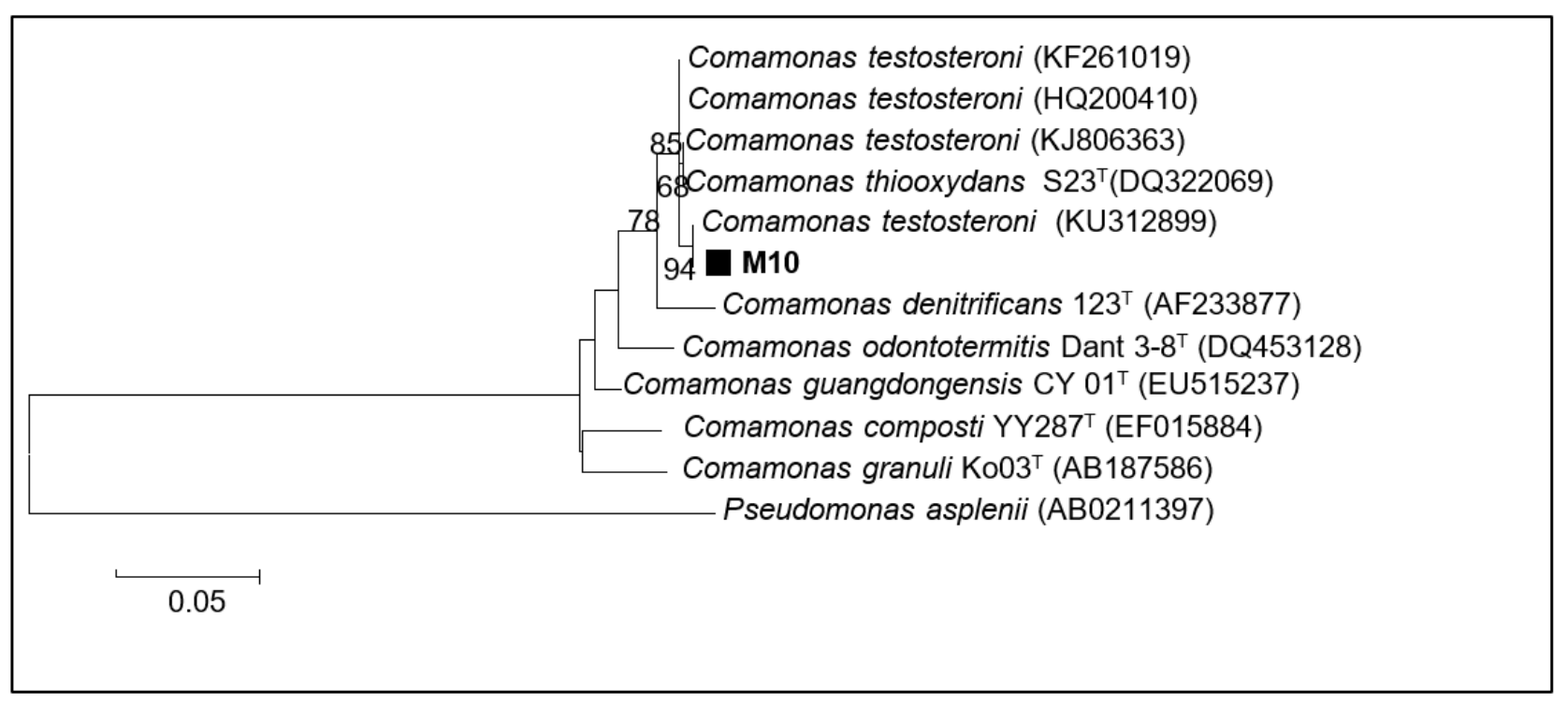

Figure 7: Maximum likelihood tree constructed using 16S rDNA gene sequences of M10 (659 bp) isolated from wet market chicken. Pseudomonas asplenii was used as outgroup. This tree was constructed using MEGA6.0 software with Kimura-2-parameter (K2) with gamma distribution (G) model. GenBank accession numbers are in parentheses. The numbers on branches are bootstrap \% from 1,000 replications (shown only when $\geq 50 \%$ ). The scale bar shows $5 \%$ sequence divergence (5 substitutions per 100 nucleotides). M10 is indicated with $\square$. Superscript "T" indicates the type strains.

\section{CONCLUSION}

In conclusion, 5 different types of antibiotic resistant bacteria which include E. coli, Klebsiella sp., Bacillus sp., Chryseobacterium sp. and Comamonas sp. were isolated from farm, supermarket, wet market and free-range chickens in Perak. The excessive use of antibiotic in the poultry farm industries had caused the emergence of antibiotic resistant bacteria which can harm the health of people consuming the chicken. To overcome this crisis, antibiotic usage in the poultry farm industries should be banned or reduced extensively. At the same time, organic poultry farming must be encouraged among the poultry farmers.

One of the ways to help reduce dependency on antibiotic usage in farm is to encourage organic farming The establishment of organic poultry farming can be achieved with the help of government authorities by providing appropriate incentive to the farmers. This incentive can be in the form of subsidy and conducting seminar on the organic chicken breeding technique for the local breeders. Further studies can be performed by isolating and identifying more antibiotic resistant bacteria from wide range of chicken types obtained locally. This will help us to obtain more information on the outbreak of antibiotic resistant bacteria in Malaysia. Based from the obtained information, preventive measures could be proposed to reduce the spread and emergence of antibiotic resistant bacteria in Malaysia.
The results obtained from this research emphasize on the importance of studying multi-resistance bacteria from different chicken sample as source of human exposure to antibiotic resistant bacteria. Therefore, not only chickens are at risks, consumers and poultry farm workers are also equally exposed to serious hazard due to emergence of antibiotic resistant bacteria in poultry industries. This calls for urgent intervention by regulatory agencies to reduce the use of antibacterial agent among poultry farms in Malaysia.

\section{ACKNOWLEDGEMENTS}

The authors are grateful to the lab staff of QIUP for technical support and to the QIUP management for the financial support. The author also would like to express deepest gratitude to Dr. Wendy Liu for helping with phylogenetic tree analysis.

\section{REFERENCES}

Adzitey, F. (2015). Antibiotic classes and antibiotic susceptibility of bacterial isolates from selected poultry. Journal of World's Veterinary 5(3), 36-41.

Alhendi, A. B., Homeida, A. A. M. and Gaili, E. S. (2000). Drug residues in broiler chickens fed with antibiotics in ration. Veterinarski Arhiv 70(4), 199-206. 
Castanon, J. I. R. (2007). History of the use of antibiotic as growth promoters in European poultry feeds. Poultry Science 86(11), 2466-2471.

Fiedler, G., Schneider, C., Igbinosa, E. O., Kabisch, J., Brinks, E., Becker, B., Stoll, D. A., Cho, G. S., Huch, M. and Franz, C. M. A. P. (2019). Antibiotic resistance and toxin profiles of Bacillus cereus-group isolates from fresh vegetables from German retail markets. $B M C$ Microbiology 19, Article no. 250.

Gerber, P., Opio, C. and Steinfeld, H. (2008). Poultry production and the environment- a review. In: Thieme, O. and Pilling, D. (eds.). Poultry in the $21^{\text {st }}$ Century: Avian Influenza and Beyond. Proceedings of the International Poultry Conference. Food and Agriculture Organization of the United Nations (FAO). pp. 379405.

Jain, V., Afzal Hussain, N. A. F., Siddiqui, T., Sahu, C., Ghar, M. and Prasad, K. N. (2017). Simultaneous isolation of Chrysobacterium gleum from bloodstream and respiratory tract: First case report from India. JMM Case Reports 4(10).

Jawad, N., Mutalib, S. A. and Abdullah, A. (2016). Antimicrobial resistance pattern of Bacillus cereus strains isolated from fried rice samples. International Journal of ChemTech Research 9(1), 160-167.

Lior, C. and Bjerrum, L. (2014). Antimicrobial resistance: Risk associated with antibiotic overuse and initiatives to reduce the problem. Therapeutic Advances in Drug Safety 5(6), 229-241.

Luna, V. A., King, D. S., Gulledge, J., Cannons, A. C., Muso, P. T. and Cattani, J. (2007). Susceptibility of Bacillus anthracis, Bacillus cereus, Bacillus mycoides, Bacillus pseudomycoides and Bacillus thuringiensis to 24 antimicrobials using sensitive automated microbroth dilution and $E$ test agar gradient diffusion methods. Journal of Antimicrobial Chemotherapy 60, 555-567.

Manual of Total Solution Provider (2012). A holistic approach to your needs in animal health. TSP Products Service Solution, Rhone Ma Malaysia Sdn. Bhd. pp. 52-57.

Selvaraj, G. K., Thian, Z., Zhang, H., Jayaraman, M. Yang, M. and Zhang, Y. (2018). Culture-based study on the development of antibiotic resistance in a biological wastewater system treating stepwise increasing doses of streptomycin. $A M B$ Express 8, Article no. 12.

Roca, I., Akova, M., Baquero, F., Carlet, J., Cavaleri, M., Coenen, S. and Kahlmeter, G. (2015). The global threat of antimicrobial resistance: Science for intervention. Journal of New Microbes and New Infections 6, 22-29.

Tanwar, J., Das, S., Fatima, Z., and Hameed, S. (2014). Multidrug resistance: An emerging crisis. Interdisciplinary Perspectives on Infectious Disease 2014, Article ID 541340.

Tsui, T. L., Tsao, S. M., Liu, K. S., Chen, T. Y., Wang, Y. L., Teng, Y. H. and Lee, Y. T. (2009). Comamonas testosteroni infection in Taiwan. Journal of Microbiology, Immunology and Infection 44, 67-71.
Vineetha, N., Vignesh, R. A. and Sridhar, D. (2015). Preparation, standardization of antibiotic and study of resistance pattern for first-line antibiotics in isolates from clinical samples. International Journal of Applied Research 1(11), 624-631.

Witte, W. (2004). International dissemination of antibiotic resistant strains of bacterial pathogens. Infections Genetics and Evolution 4, 187-191. 